S U M A R I O

Magdalena López y Arturo Matute Castro, (Dis)locaciones narrativas: arte y literatura actual en la República Dominicana y Cuba... ... . . . . . ...

\title{
I. EsTUDIOS
}

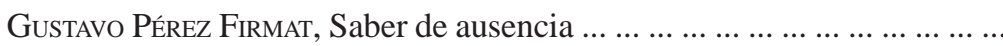

Miguel D. Mena, Ciudades revisadas: la literatura pos-insular dominicana

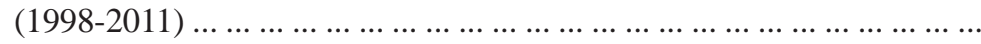

JORGE ForNET, Elogio de la incertidumbre. Cuba novelada en el siglo XXI

Rita De Maeseneer y Fernanda Bustamante, Cuerpos heridos en la narrativa de Rita Indiana Hernández, Rey Emmanuel Andújar y Junot

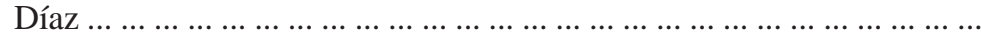

Rafael Rojas, La prole de Virgilio: vaivenes de la recepción de Virgilio

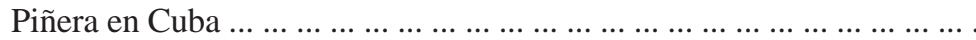

Fernando Valerio-Holguín, Juan Bosch: el último cuentista dominicano

Emilio Bejel, José Martí: el ojo del canario: cine, fotografía y duelo de

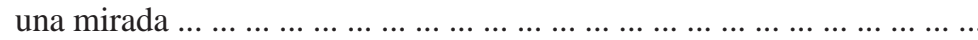

LoRna ToRRADo, Travesías bailables: revisión histórica en la música de

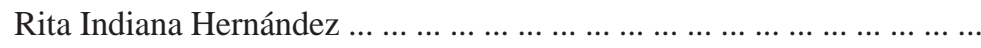

Damaris Puñales-Alpízar, Soy Cuba, Océano y Lisanka: de lo alegórico a lo cotidiano. Transformaciones en las coproducciones cubano-

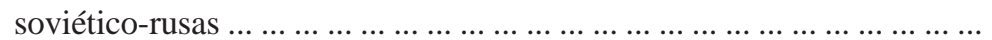

Silvio ToRres-Saillant, Peregrinaciones antillanas: sobre el saber

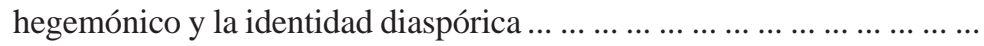


Danny Méndez, De travestismos sospechosos y seducciones peligrosas: la identidad sexual en dos cuentos de José Alcántara Almánzar ... ... ... .

Zaida Capote Cruz, Los desafíos de la libertad. Narradoras cubanas de

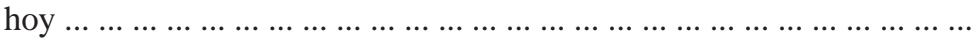

Dawn Duke, Literatura afro-femenina en la República Dominicana. ¿Una

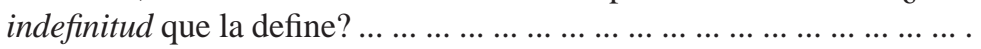

Carlos Uxo GonzÁlez, Personajes afrocubanos en la narrativa cubana del nuevo milenio: 2000-2009

\section{RESEÑAS}

Magdalena López sobre Ana María Amar Sánchez, Instrucciones para la derrota: narrativas éticas y políticas de perdedores .....................

Rocío Quispe-Agnoli sobre Elena Altuna, Retórica del desagravio. Estudios

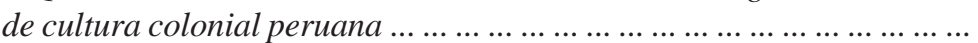

EnRIQUe Rodrigues-Moura sobre Ralph Bauer y José Antonio Mazzotti, eds., Creole Subjects in the Colonial Americas. Empires, Texts,

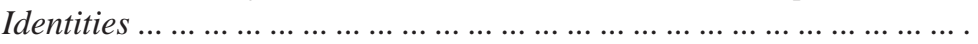

FERnANDa Zullo sobre Darlene J. Sadlier, ed., Latin American Melodrama:

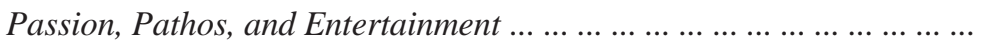

Ángeles MAteo-Del-Pino sobre Fernando A. Blanco, Desmemoria $y$ perversión: privatizar lo público, mediatizar lo íntimo, administrar lo privado ......................................................... ...

Clara Eugenia Ronderos sobre María Mercedes Andrade, Ambivalent Desires: Representations of Modernity and Private Life in Colombia (1890's-1950's)

Gonzalo Lamana sobre Catherine Burns, Into the Archive. Writing and Power in Colonial Peru ... ... ... ... .................................. . . .

Marcelo Rioseco sobre Rubí Carreño, eda. Diamela Eltit: redes locales, redes globales 